\title{
Pela promoção do ensino de Literatura: uma política para o professor leitor
}

\author{
Alexandra Santos Pinheiro
}

UFGD - MS

\begin{abstract}
Resumo
O trabalho em cursos de Formação Continuada de professores tem nos mostrado uma distância entre a proposta dos Parâmetros Curriculares e a prática docente. Desta forma, à luz de pesquisas sobre o Ensino de Literatura e sobre a formação de leitores, refletimos sobre o papel do professor, principal mediador entre livro e aluno. Discute-se a necessidade de se trabalhar a partir da convicção de que a leitura literária exerce a função humanizadora, cognitiva, social e psicológica e que a disciplina, portanto, não deve estar em sala de aula pelo viés da obrigatoriedade. Pensa-se, finalmente, que a promoção da leitura literária exige, dentre outros elementos, a intervenção do professor leitor, com ações pedagógicas marcadas por fundamentação teórico-metodológica, uma vez que, ao professor, cabe selecionar a grande quantidade de obras oferecidas pelo mercado editorial.
\end{abstract}

Palavras-chave: literatura, ensino, políticas públicas.

O presente ensaio tratará do tema "Literatura no Ensino Fundamental e no Ensino Médio” a partir de três perspectivas: a importância e a função da Literatura para a formação humana, social, cognitiva e subjetiva do homem e seu ingresso na escola; a concepção de leitura e de leitor literário que poderia amparar o trabalho docente; e a importância da formação do graduando e da formação continuada para o efetivo ensino de Literatura.

Atreladas às questões que destacamos estão outros debates, como: políticas públicas de leitura; a seleção de obras diante de um mercado editorial que oferece inúmeros títulos, principalmente para o Ensino Fundamental; a falta de diálogo entre escola, professores, órgãos públicos e comunidade; e o uso que se faz nas escolas dos livros didáticos. Como se pode perceber, tratar do ensino de Literatura implica caminhar por vários desafios. Assim, como se faz necessário delimitar o caminho a percorrer para a elaboração desta analise, optamos apenas pelos três pontos apresentados.

O referencial teórico que sustenta a análise é pautado em pesquisas que confirmam a importância de se pensar a prática e a teoria mais significativas para o ensino de Literatura. Em primeiro lugar, contamos com a análise proposta pelos Parâmetros Curriculares Nacionais (1998) e as Orientações Curriculares Nacionais (2006). Os Parâmetros, conforme 
destacou Maria Alice de Faria, dedicaram ao ensino de Literatura pouco mais de uma página, englobando a disciplina numa área maior: a da Linguagem. As Orientações Curriculares, por sua vez, vão destacar alguns equívocos cometidos pelos PCN, salientando a necessidade de se repensar as fundamentações teóricas e metodológicas do ensino de Literatura, pois só assim seria possível a transformação de um ensino que, geralmente, vê a arte literária de forma utilitarista: no Ensino Fundamental, como forma de moralizar ou ensinar gramática e outras áreas das Ciências Humanas; no Ensino Médio, como preparação para o vestibular.

Regina Zilberman é trazida para o debate porque a obra Literatura em crise na escola (1882), organizada por ela, traz autores que sistematizam o debate em torno do ensino de Literatura, versando sobre problemáticas e apontando soluções que ainda são recorrentes nos mais recentes estudos sobre o tema: políticas públicas de leitura; desigualdade social, o acesso ao livro; os equívocos das práticas de leitura levadas para sala de aula; e o desencontro entre escola, governo, comunidade e família, uma vez que a formação de leitores seria um trabalho em conjunto.

Não poderia faltar, nesse ensaio, o diálogo com a obra A leitura e o ensino de leitura (1988), também de Regina Zilberman. Trata-se de uma pesquisa dedicada a várias questões que norteiam o ensino da Literatura, tópicos recuperados e redimensionados por outros autores, mas que trazemos à luz por ser um dos pioneiros na pesquisa de ensino de Literatura. Apesar de ter sido lançado no final da década de 70, a obra versa sobre temas atuais, já que muitos dos desafios apontados pela pesquisadora ainda permanecem no século XXI: democracia, concepção de leitura e a importância do texto literário lido na integra, não por fragmentos. Desse livro, destacamos, em especial, o capítulo em que a autora trata da importância da teoria literária para o trabalho docente nos Ensinos Fundamental e Médio. Essa questão também é destacada por Rildo Cosson (2006), quando apresentou, em seu livro Letramento Literário, a importância do suporte teórico para a prática docente.

Se a teoria é um fator significativo para a prática docente, não poderia faltar em nosso referencial teórico a obra de Maria da Glória Bordini e Vera Teixeira Aguiar (1993). As autoras apresentam algumas metodologias teóricas para conduzir o ensino de Literatura. Das metodologias destacadas, percebemos, no diálogo com professores, em projetos de formação continuada, que o método criativo é o mais utilizado em sala de aula. Todavia, conforme apresentaremos no decorrer desta exposição, isso é feito, muitas vezes, de forma equivocada.

A última obra que merece ser destacada como referencial teórico do presente ensaio é Caminhos para formação de leitores (2004), organizada por Renata Junqueira. Trabalhamos, 
em especial, com o capítulo “Formação de leitor e razões para a Literatura”, de Ricardo Azevedo. Embora esses autores sejam as principais referências teóricas desse ensaio, no decorrer da análise outros nomes serão citados para enriquecer o debate. Após a apresentação do referencial teórico, entramos nas questões que norteiam o ensaio: a importância e a função da Literatura e o seu ingresso na escola; a concepção de leitura e de leitor literário; e a importância do trabalho docente para que efetivas práticas de leitura possam promover a formação de leitor.

Ao longo do século XIX, a Literatura foi amparada pela crença de que a palavra tinha um poder ilimitado e de que a sua prática era uma espécie de veículo tradutor da realidade, com o poder de espelhar o mundo e seus contornos. Hoje, a visão da Literatura busca, como afirma Marisa Lajolo (2002), a "grande aventura da significação provisória”, transformando esse provisório na "arma de sua permanência”. A arte literária passa a ser vista como “instauração de uma realidade, apreensível apenas na medida em que permite o encontro de escritor e leitor sem que, entre ambos, haja qualquer acordo prévio quanto a valores, representações, etc” (Lajolo, 2002, p. 33).

Diante de uma sociedade tão tecnológica, com importantes descobertas científicas, em que o indivíduo na mais tenra idade tem acesso à Internet e a partir dela ouve música, joga, assiste a filmes, conhece lugares e pessoas, por que insistir na Literatura (no livro literário)? Por que se empenhar que nossos alunos (e nós também) tenham na obra literária uma opção para o prazer, para o conhecimento e para a formação subjetiva e social? Nas palavras de Roland Barthes encontramos um primeiro argumento em defesa da permanência ou da implantação da leitura literária: "Se, por não sei que de excesso de socialismo ou barbárie, todas as nossas disciplinas devessem ser expulsas do ensino, exceto uma, é a disciplina literária que deveria ser salva, pois todas as ciências estão presentes no monumento literário” (Barthes, 1980, p. 6).

A afirmação do estudioso pode ser sustentada, inclusive, com a Teoria da Literatura Comparada, responsável por mostrar o quão tênue é a fronteira entre a Literatura e outras áreas do saber: Pintura, Música, Antropologia, Sociologia, Psicologia, História, etc. Mas nem o belo depoimento de Barthes nem a Literatura Comparada são suficientes para amenizar a chamada crise de leitura debatida no Brasil desde a década de 1970. Regina Zilberman (1988) mostra algumas contradições em relação à chamada crise de leitura. De acordo com sua pesquisa, nos anos 70, quando se iniciaram efetivamente as reflexões sobre a (não) leitura, acontecia o crescimento da população urbana, decorrente da oferta de trabalho nas indústrias. 
Esse aumento populacional, por sua vez, exigiu uma reformulação da estrutura escolar devido à ampliação do número de alunos. Assim, dentre as novas propostas pela reforma de ensino instituída nesse período, o texto literário ganha destaque em sala de aula, as editoras passam a investir na publicação de obras infantis e um elevado número de livros passa a circular nos acervos escolares.

Os apontamentos históricos que apresentamos demonstram que, aparentemente, não há lugar para a chamada crise de leitura. Se houve o aumento do público leitor e a ampliação na oferta de obras literárias, onde estaria a crise? De acordo com Zilberman, a contradição instalava-se na recusa à leitura. O público leitor, em potencial, não demonstrava interesse pela leitura das obras literárias. Essa recusa, infelizmente, ainda é a motivação para o debate acerca do ensino de Literatura. A diferença é que ao debate são acrescidos outros (não) leitores: os professores e a família.

Por outro lado, a concepção de Literatura relaciona-se, diretamente, com a questão da leitura, entendendo-a como um processo de construção de sentidos. Como afirma Vernier, “escrever, como ler, é sempre lançar questões à linguagem, às normas estéticas estabelecidas” (1977, p. 24). Antonio Candido afirma que a Literatura tem a capacidade de "confirmar a humanidade do homem", derivando, entre suas funções a de "satisfazer à necessidade universal de fantasia, contribuir para a formação da personalidade e ser uma forma de conhecimento do mundo e do ser” (cf. Candido, 1972, p. 12). Pela importância que acreditamos ter a Literatura, observamos o quanto ela merece uma discussão contínua, na medida em que tanto o fato literário como a crítica e a teoria estão ligados ao momento histórico em que são produzidos.

Por relacionarmos os problemas enfrentados pelo ensino de Literatura às questões que envolvem a "crise da leitura” é que chamamos para pauta a análise de políticas públicas direcionadas a atenuar a flagrante falta de compromisso com a leitura por parte de pais, da escola, dos alunos e de autoridades políticas. Vale lembrar que entendemos por políticas públicas as ações, programas e projetos de governo (e parcerias privadas), previstos em orçamentos que visam à melhoria da qualidade de vida dos cidadãos. As políticas podem envolver os setores de saúde, lazer, moradia, educação, dentre outros setores. Para a proposta desse texto, interessam as direcionadas à educação, mais especificamente as ações que objetivam promover práticas de leituras.

Os programas de políticas públicas nascem da necessidade (demandas). Há um bom tempo, existiu a necessidade de criar escolas gratuitas para que todos tivessem acesso à 
cultura letrada; depois, a necessidade passou a ser outra: assegurar um ensino de qualidade para todos, exigindo que os programas de políticas públicas se organizassem nesse sentido. A questão da (não) leitura surge quando se constata que a maior parte dos que se intitulam alfabetizados não consegue compreender os múltiplos sentidos de um texto e tem dificuldade de expressar suas idéias. Nesse sentido, vale citar pesquisas que apontam que o ensino da leitura é feito de forma funcional, como denomina Kleiman (1989), ou seja, a aprendizagem ocorre a partir de situações artificiais de comunicação e expressão, com atividades restritas à interpretação de textos didáticos.

Instalada essa nova necessidade em relação à precariedade da leitura nas escolas, os governos passam a financiar, muitas vezes em parceria com órgãos privados, programas direcionados a resolver a questão. Bienal do livro, Baú ambulante, Fome de livro são alguns dos projetos mais conhecidos. Paralelamente a isso, o orçamento também é destinado à construção de bibliotecas, à ampliação de acervos públicos e à formação continuada dos profissionais da educação. Quando os programas e ações tornam-se concretos, surgem novas problemáticas; dentre elas, podemos citar o fato de que nem sempre a proposta corresponde ao contexto onde a unidade escolar está inserida. Apesar do investimento na formação continuada, muitos professores não se conscientizaram de que são peças importantes para que sejamos, efetivamente, um país de leitores. Desmotivados pelos baixos salários e pelas condições de trabalho, muitos docentes não encontram tempo para a leitura; além disso, não vêem na formação de um cidadão reflexivo uma possibilidade para que, no futuro, as condições de trabalho da classe sejam revistas. A experiência que passaremos a relatar deseja demonstrar que as ações públicas descontextualizadas da realidade escolar e sem pessoas comprometidas a trabalhar para que determinadas necessidades sejam supridas estão fadadas ao fracasso.

Em 2004, fizemos parte de um trabalho de parceria entre a universidade em que atuamos e a prefeitura de uma pequena cidade do Paraná. A Secretaria Municipal de Educação tinha conseguido verba dos governos estadual e municipal para ampliar o acervo das vinte escolas do campo daquele município. O nosso trabalho consistia em orientar os professores a utilizarem as obras de Literatura Infanto-Juvenil (para esse gênero foi destinada a maior parte da verba). A Secretária da Educação dividiu conosco um pouco de sua expectativa em relação ao trabalho e sugeriu atividades como: pintar nas paredes da escola os personagens preferidos dos alunos (para isso ela já contava com o talento de uma professora de artes), organizar uma semana de teatro, quando cada turma poderia encenar sua história preferida, etc. Valorizamos as suas sugestões, mas questionamos a metodologia, explicando a 
ela que antes de tudo partiríamos da leitura das obras, priorizaríamos a leitura do texto literário e o debate de suas múltiplas interpretações.

Quanto a isso não houve discordância; o problema surgiu quando sugerimos um trabalho que envolvesse a comunidade, que convidasse os pais para consultar o acervo e levar o livro para casa, podendo lê-lo com seus filhos. A Secretária nos explicou que os livros eram novos e que, para conservá-los, eles não poderiam sair das escolas. Mesmo desmotivados com o posicionamento da responsável pelo projeto de leitura, decidimos seguir com o trabalho, afinal, havíamos protocolado um projeto de extensão universitária.

Como havia vinte escolas, dividimo-nos em pequenos grupos para atender a todas. Amparados por uma metodologia previamente definida, fomos, cada grupo, passar um dia nas escolas do campo. A primeira etapa do trabalho consistia em ajudar os professores (não houve aula naquele dia) a catalogar os títulos; depois, pedimos que cada um escolhesse o livro que já tivesse lido e gostado. Para nossa surpresa, nenhum professor havia consultado qualquer um dos livros (que já estavam lá há um bom tempo) para ler. As justificativas foram ainda mais estarrecedoras: falta de tempo, problemas particulares. Uma resposta em especial fez-nos rever a metodologia do trabalho. Uma professora explicou, mais ou menos nessas palavras: "não adianta; os alunos, quando não estão aqui, precisam trabalhar com os pais na roça, eles não têm tempo para livros” (ela se referia a crianças do primeiro segmento do Ensino Fundamental). Como o dia dos demais colegas também tinha sido frustrante, mudamos a proposta e passamos a incentivar a leitura entre os professores. Depois, partimos para a aplicação em sala de aula das leituras realizadas e conseguimos alguns bons resultados. O melhor deles foi ter convencido a Secretária da Educação a permitir que os pais participassem do projeto.

Em Invasão da Catedra, Ligia Chiappini Leite (1983) apresenta um novo olhar sobre a leitura. A pesquisadora acredita ser importante a leitura do mundo, mas defende também que a visão que apregoa uma leitura desinteressada deve ser trazida para as classes populares. Assim, essa camada da sociedade não veria mais a prática de leitura como algo pragmático e utilitarista. Quando os professores do referido município negaram o empréstimo de livro aos pais, por temerem que as obras fossem estragadas, estavam mistificando o livro e impossibilitando que os moradores de comunidades rurais, a maioria com baixo nível de escolaridade tivesse acesso à leitura descompromissada do pragmatismo atribuído a ela.

A partir dessa experiência de políticas públicas de leitura, vislumbramos alguns equívocos. O orçamento foi direcionado à ampliação de um acervo; todavia, ele não poderia 
ser consultado pelos pais, com a justificativa de que os livros não fossem estragados. Por outro lado, o acervo adquirido não chamou a atenção dos professores porque não viam sentido em incentivar a leitura entre alunos que precisavam trabalhar na roça. Não pretendemos negar a importância de políticas públicas de leitura; desejamos, apenas, salientar que não basta o recurso financeiro para a construção de bibliotecas e a compra de livros. É preciso somar a esses esforços, dentre outras ações, uma transformação socioeconômica (direcionada à construção de uma sociedade menos desigual) e uma maior motivação do professor. Sabemos que o docente tem muitas razões para a desmotivação. Além dos baixos salários, a maioria dos professores do Ensino Fundamental são mulheres, chefes de família, que têm até 3 jornadas de trabalho. Podemos citar também a precarização do trabalho do professor, com longas jornadas e o estresse a que estão sujeitos cotidianamente devido à violência e à falta de apoio.

Por isso, acreditamos que os projetos de formação continuada devem ser acompanhados de melhorias salariais e de melhores condições de trabalho. É preciso que o professor não seja obrigado a trabalhar com a leitura, ele precisa acreditar na importância desse trabalho, na função humanizadora da Literatura. Como afirma Bordini (1988, p. 18), para que a leitura da obra literária ocorra, é preciso, dentre outros elementos citados pela autora, que exista o "professor leitor com boa fundamentação teórica e metodológica”, pois é ele quem vai selecionar a grande quantidade de obras oferecidas pelos mercados editoriais.

Nos cursos de formação de professores, insistentemente lembramos que só ensinamos o que sabemos. Alertamos ainda que com as crianças e os adolescentes a política do "faça o que eu digo, não o que eu faço” não emplaca. Mesmo assim, é comum ouvirmos depoimentos em que os professores colocam-se como sujeitos desmotivados financeiramente e desvalorizados demais para trocar a novela das oito pela Literatura: “é minha hora de lazer”, afirmou, no ano passado, uma professora do $5^{\circ}$ ano do município onde trabalhávamos. De certa forma, essa professora tinha razão. Embora a obra literária possa, como aponta Antonio Candido (1972), contribuir para refletir sobre a vida e o mundo, oferecendo mecanismos para compreender nossas subjetividades, nossas alteridades, a questão da sexualidade, da morte e da ética, para citar apenas alguns pontos, o ato de ler é um processo trabalhoso que exige “esforço, treino, capacitação e acumulação” (AZEVEDO, 2004, p38).

Já que entramos na questão do debate sobre leitura, antes de analisar o lugar da Literatura nos Parâmetros Curriculares, é importante apresentar o que entendemos por leitura e leitor. Sobre a definição de leitura, optamos pela realizada por Eni Orlandi (2006, p. 23), 
que, pela visão da Análise do Discurso, define a leitura como "compreensão, não apenas decodificação”. A leitura seria o momento crítico da construção do texto, um processo de interação verbal que faz desencadear a assimilação dos sentidos. O leitor, por sua vez, é aquele que consegue atribuir sentido a um diversificado número de livros. É leitor aquele que, devido à familiaridade com o texto escrito (citaremos apenas o escrito por ser ele o foco de nossa reflexão) consegue diferenciar os tipos de gêneros literários e não-literários e os motivos que o levam a escolher uma leitura em detrimento da outra.

É por isso que o professor citado anteriormente tinha razão ao distanciar leitura de prazer. Para que a leitura seja inserida como uma forma de aproveitar o tempo livre, ou seja, para que seja vista como lazer, faz-se necessário que o indivíduo torne-se um leitor e esse processo, como vimos, exige esforço, treino e dedicação. É necessário saber por que lemos, precisamos atribuir sentido ao que lemos e isso exige prática, treino, acúmulo de informação, raciocínio. A arte literária, se observada pela afirmação de Barthes, deveria fazer parte do ambiente familiar e escolar desde os primeiros meses de vida. Essa afirmação pode parecer utópica, mas não é. Ela está fundamentada em um referencial teórico que nos permite acreditar que a democratização do ensino exigiria um repensar sobre nossa história sócioeconômica de exclusão.

Ao tratar da prática do educador, Pedro Demo (1999) afirma que ela (a prática) deve estar pautada na teoria, que deve, por sua vez, ser confrontada com a realidade histórica. Como ficaria, diante das apreciações acima, o Estágio Supervisionado de Literatura nos cursos de Letras? Acreditamos que essa disciplina carrega a responsabilidade de formar professores com conhecimento teórico para atuar no ensino de Literatura, educadores que adotem uma prática coerente com o referencial teórico e com a realidade social, econômica e histórica do grupo que pretende formar. Nesse sentido, a disciplina do Estágio é a responsável por fazê-los refletir sobre a teoria e a prática.

Em relação ao debate sobre o ensino de Literatura, a problemática mais simples de ser resolvida é a que valida a sua inserção na sala de aula. Primeiramente, porque contamos com um arcabouço teórico que sustenta a sua importância para a formação ética, psicológica e cognitiva do cidadão; depois, porque ela está amparada pelos Parâmetros Curriculares Nacionais. O complicador seria convencer os professores a se tornarem leitores a fim de contribuírem de forma significativa para a formação de alunos leitores. Essa é uma questão que exige de nós uma compreensão sócio-histórica que envolve o professor (não) leitor; exige, também, discutir a injusta distribuição de renda praticada no Brasil. Obviamente, não é 
possível atribuir ao educador a culpa pela falta de uma política escolar que priorize a leitura para formação dos alunos. Por outro lado, não podemos pensar em políticas de leitura se o mediador entre o livro e o educando (e aqui entram professor e pais) demonstrar pouca ou quase nenhuma familiaridade com a leitura.

Nos Parâmetros Curriculares Nacionais, a Literatura é colocada ao lado do ensino da gramática e de redação, numa proposta de se trabalhar a linguagem em toda sua complexidade, evitando a fragmentação proposta pela lei 5692/71. Nesse sentido, a Literatura contribuiria para desenvolver nos estudantes todas as competências e habilidades estipuladas pelos PCN: representação e comunicação; investigação e compreensão; contextualização sócio-cultural.

Um olhar mais atento às propostas curriculares, todavia, indica que o conteúdo selecionado para o ensino de Literatura não possibilita desenvolver a competência da expressão e interpretação do texto. Como demonstram as Orientações Curriculares para o Ensino Médio, o texto literário nos PCN ocupa um lugar secundário; o foco principal é dado à história, às escolas e às tendências literárias. Marisa Lajolo (2002, p. 21) também aponta para a necessidade de se discutir a historiografia do texto e tratar das críticas feitas a uma determinada obra, mas lembra que essas questões não devem substituir a leitura e a interpretação da obra literária: “é fundamental interpretá-lo, perceber os impasses individuais (leitor com ele mesmo) e sociais que a obra oferece”.

Mesmo que a proposta dos PCN precise ser repensada em relação ao ensino de Literatura, a disciplina está lá, apresentada como importante instrumento de formação do indivíduo. O problema é que, quando o professor atua em sala, ele geralmente se baseia nos fragmentos literários encontrados nos livros didáticos e na síntese das características literárias na qual determinado autor e obra estão inseridos. Mas como formar professores leitores? Quem trabalha com formação continuada sabe que a tarefa não é das mais simples. Nos cursos há expectativa por receitas de como ensinar: “Como fazer com que os alunos gostem de poesia?”; “Como trabalhar o Romantismo com jovens do século XXI?”. Perguntas desse tipo poderiam encher folhas de papel, mas a resposta a elas pode ser dada a partir de uma única pergunta: “Qual o último livro literário que você leu?”. Como geralmente são poucos os que se lembram do último título lido, o encontro começa com o tema "a importância do professor leitor”. Vale retomar a importância do Estágio Supervisionado em Literatura. Nessa disciplina, os estagiários podem ser orientados em projetos de extensão e pesquisa que lhes possibilitem perceber a diferença entre um professor leitor e um professor não leitor. Se 
conseguirmos que ele adote a postura do professor leitor, teremos mais um aliado na construção de uma escola verdadeiramente democrática.

Pelas ponderações levantadas até o momento, já percebemos a principal direção metodológica no ensino de Literatura - a leitura do texto literário. Marisa Lajolo (2002, 24) lembra que em nome da "motivação", as obras literárias são, muitas vezes, dadas de forma equivocada na sala de aula. A autora lembra que o primeiro contato com o texto literário deve ser a partir da leitura dele, não de seus fragmentos. Dramatizações, perguntas sobre o enredo, sobre a época, palavras cruzadas e outras atividades não devem substituir a leitura individual.

Não queremos abordar todos os procedimentos metodológicos para que o ensino de Literatura se concretize em sala de aula; apenas citaremos a pesquisa de Glória Bordini (1988, pp. 7-21) para mostrar que há fundamentações teóricas que possibilitam ao educador se sentir seguro com o ensino da disciplina. Um dos passos que antecedem a leitura integral da obra literária sugeridos por Bordini é o professor proceder à seleção das obras, considerando a idade e o interesse de um determinado grupo de alunos. Nesse sentido, a faixa etária que nos interessa seria a dos 9 aos 17 anos. Esse período corresponde ao processo em que, aos poucos, a criança começa a romper com o estágio de fantasia e vai exigindo leituras com conteúdo intelectual, literatura engajada, romances históricos. Respeitar a faixa etária e compreender os interesses que norteiam cada fase seria, então, um primeiro procedimento metodológico para o trabalho com a leitura. Um segundo passo seria oferecer a eles a leitura individual do texto e, em seguida dar-lhes a oportunidade de expressarem as impressões que o texto oferece. A autora segue com várias sugestões de atividades, mas nenhuma delas será bem sucedida se durante a seleção das obras o professor não tiver o seu momento individual de leitura.

Assim, para selecionar da quantidade de obras voltadas ao público infanto-juvenil as que mais correspondam ao compromisso literário de formação humanizadora, intelectual, artística e psicológica do sujeito, faz-se necessária a atuação do professor. Mais uma vez o docente é colocado em pauta porque consideramos ser ele o principal mediador entre o livro e o educando, principalmente aquele oriundo de lares que não contam com pais leitores ou com pais que disponham de recursos financeiros para oferecer livros aos seus filhos. Para executar essa tarefa, é preciso que o professor seja leitor e acredite na importância da leitura literária para a formação de seus alunos.

Quando observamos nos acervos escolares livros literários que se prestam a didaticamente escrever sobre as angústias do público infanto-juvenil, lembramos do esforço de Monteiro Lobato em fazer do Brasil um país de leitores. Seu projeto de escrever a partir do 
contexto da criança, colocando-a como protagonista de suas histórias foi conciliado com uma apurada linguagem artística. Os debates que suas obras suscitam não são explícitos, mas trabalhados a partir da complexidade da criação de suas personagens. Poucos autores produzem hoje uma literatura desvinculada do didático. Lygia Bojunga merece ser citada como uma autora que não se rende ao estipulado pelo mercado editorial. Suas obras são de uma riqueza estilística impar, porém, como constatamos na maioria das escolas que acompanhamos, poucas vezes seus livros são levados à sala de aula e, vale dizer, raras são as escolas que possuem um título da autora. Talvez porque as suas obras exijam um esforço interpretativo que muitos professores ainda não têm, devido, também, à história de vida, aos escassos recursos para o acesso aos livros, pela falta de um mediador que os ensinasse que a prática da leitura é algo construído, aprendido com o tempo e com as diferentes experiências de leitura.

A história da cultura letrada do Brasil (que não é diferente de outros países) revela que o acesso a essa cultura sempre foi privilégio de poucos. Os filhos de operários eram (e ainda são) direcionados aos cursos técnicos, de formação de mão obra, os filhos da elite dominante eram/são preparados para o curso superior, para os estágios na Europa. A democratização da leitura, como sugere Zilberman (1988), é a garantia de que a leitura não seja um mecanismo de exclusão. O acesso aos conhecimentos que a Literatura oferece deve ser destinado a todos. Sabemos ainda que, na maioria das vezes, as experiências de leitura dão-se nas escolas; por isso, se o aluno não tiver contato com os clássicos nesse período, poderá não ter outra chance de conhecê-los. Mas para mudar essa mentalidade, num país em que a injusta distribuição de renda não permite a todos a compra de livros, é preciso mudar a postura dos professores, vistos por nós como os principais mediadores entre o livro e o leitor.

Como foi possível observar, procuramos demonstrar que, num país marcado por uma injusta distribuição de renda, é na escola que, geralmente, a maior parte das crianças e dos jovens tem acesso à leitura de obras literárias. Conseqüentemente, colocamos o professor como importante mediador para que esse contato se estenda para fora da escola. Tentamos compreender os limites desse professor e, por isso, sinalizamos a necessidade de uma atuação significativa do programa de formação continuada. Contudo, antes de encerrar o debate, trouxemos para pauta outro fator que deveria preparar o professor para a atuação crítica enquanto mediador no processo de formação de leitores: os cursos de licenciatura, especialmente o de Letras. Enquanto mandarmos para salas de aula professores sem preparo teórico e metodológico para o ensino de leitura literária, ficaremos à mercê da imposição do mercado editorial e as políticas públicas de leitura não atingirão seus objetivos. 


\section{REFERÊNCIAS}

Azevedo, R (2004). Razões para a formação de leitores. In R. J. Souza (org.), Caminhos para a formação do leitor (pp.37-43). São Paulo, SP: DCL.

Barthes, R. (1980). Aula. São Paulo, SP: Cultrix.

Bordini, M. da G. \& Aguiar, V. T. (1988). Literatura: a formação do leitor: Alternativas metodológicas. Porto Alegre, RS: Mercado Aberto.

Borelli, S. H. S. (1996). Ação, suspense, emoção. Literatura e cultura de massa no Brasil. São Paulo, SP: EDUC.

Candido, A. (1973). Literatura e sociedade. São Paulo, SP: Companhia Nacional.

(1972). A literatura e a formação do homem. Ciência e Cultura, 9(24), 803-9. (A função humanizadora da literatura) Bunesp-Marília, BFE-USP, BCSL-UNITAU

Chiappini Leite, L. (1983). A invasão da cátedra. São Paulo: Mercado aberto:

Cosson, R. (2006). Letramento literário: Teoria e prática. São Paulo, SP: Contexto.

Demo, P. (1999). Pesquisa: Princípios científico e educativo. São Paulo, SP: Cortez.

Faria, M. A. (1999). Parâmetros curriculares e literatura: As personagens de que os alunos realmente gostam. São Paulo, SP: Contexto.

Kleiman, A. (1989). Leitura, ensino e pesquisa. São Paulo, SP: Pontes.

Lajolo, M. (2002). Do mundo da leitura para a leitura do mundo. São Paulo, SP: Ática.

Martins, A. (2005). Interlocuções do livro didático com a literatura. In Literatura e letramento: Espaços, suportes e interfaces - O jogo do livro. Belo Horizonte, MG: Autêntica/CEALE/FAE/UFMG.

Ministério da Educação, Secretaria de Educação Fundamental. (1998). Parâmetros curriculares nacionais: Terceiro e quarto ciclos do Ensino Fundamental: língua portuguesa. Brasília, DF: MEC/SEF.

Ministério da Educação, Secretaria de Educação Média e Tecnológica. (1999). Parâmetros curriculares nacionais: Ensino Médio. Brasília, DF: MEC.

Ministério da Educação e do Desporto, Secretaria de Educação Básica. (2006). Orientações curriculares para o Ensino Médio. Brasília, DF: MEC/SEB.

Orlandi, E. P. (2006). Discurso e leitura. $7^{\mathrm{a}}$ ed. São Paulo, SP: Cortez.

Souza, R. J. de. (Org.) (2004). Caminhos para a formação do leitor. São Paulo, SP: DCL.

Vernier, F. (1977). A escrita e os textos: O fenômeno literário. Portugal: Editorial Estampa. 
Zilberman, R. \& Magalhães, L. C. (1987). Literatura infantil: Autoritarismo e emancipação. São Paulo, SP: Ática.

Zilberman, R. (Org.) (1988). Leitura em crise na escola: As alternativas do professor. 9a ed. Porto Alegre, RS: Mercado Aberto.

Zilberman, R. et al. (1995). Natureza interdisciplinar da leitura e suas implicações na metodologia do ensino. In M. Abreu (Org.). Leituras no Brasil: Antologia comemorativa pelo $10^{\circ}$ COLE. (pp. 83-121). Campinas, SP: Mercado de Letras/Associação de Leitura do Brasil.

\begin{abstract}
A AUTORA
Alexandra Santos Pinheiro é Doutora em Teoria Literária pela Unicamp. Atualmente é professora adjunta da Faculdade de Comunicação, Artes e Letras na Universidade Federal da Grande Dourados (UFGD). Atua como pesquisadora em historiografia brasileira e ensino de literatura como integrante do grupo de pesquisa: NÚCLEO DE ESTUDOS LITERÁRIOS E CULTURAIS. E-mail: alexpin24@yahoo.com.br.
\end{abstract}

